\title{
Evaluation of the Open Pit Vehicles Loading Influence on the Reliability of Motor - Wheel Reducers
}

\author{
Stenin Dmitriy V. ${ }^{\mathrm{a}}$, Stenina Natalia A. ${ }^{\mathrm{b}}$, Bakanov Alexander A. $^{\mathrm{c}}$ \\ T. F. Gorbachev Kuzbass State Technical University, \\ Kemerovo, Russian Federation. \\ astenindv@mail.ru, ${ }^{5}$ stnat33@mail.ru, ${ }^{\mathrm{c}}$ alekbakanov@yandex.ru
}

\begin{abstract}
The purpose of the work is to increase efficiency in the use of dump trucks in open pit mining by improving operational reliability, reducing bounce rates, reducing the length of the vehicle repairing and, as a result, the cost of the final product.

The article describes how to improve the reliability as well as the efficiency of the use of trucks operating in open-pit mining. The work's result is the methodology that allows defining of the loading reliability of all vehicles. The study is based on the data obtained experimentally in real conditions of operating trucks. During the processing of the experimental data, regression dependences were obtained of the oil temperature in the gears of the motorized wheels of quarry trucks on the factors that characterize the operating conditions. Also, the degree of influence of each of the said factors on the oil temperature was assessed. Subsequently, using the obtained dependences, the practical problem of determining the length of vehicle repair was solved.

This work has a great scientific and practical importance because the results can determine the rational values of loading of dump trucks used in open pit mining, measuring the operating conditions.
\end{abstract}

Keywords - open-pit vehicle, motor-wheel reducer, oil temperature, reliability, vehicle loading.

\section{INTRODUCTION}

The most common vehicles used in open-pit mining are vehicles with 130-220 tons capacity, mainly Belaz. [1].

The analysis shows that the intensity of decrease of the technical availability of quarry trucks is $1.8-3 \%$ per year [2].

Working conditions of vehicles that have had a negative impact on the efficiency, reliability and, as a result, the cost of the final product, impose higher requirements to the oil and lubricant materials to be used in operation. Properties of such materials change more intensely than the parameters of the technical condition of the elements of the car, and serve as an indicator of the condition of the components and units.

The cause of oil temperature rise in the quarry truck motorized-wheels reducer (MWR) is the deterioration of its technical condition [3]. The thermal behavior of MWR is interrelated with parameters of its state varying from the nominal to the limit ones. Changing the technical condition of MWR and other units of the quarry vehicle depends on the modes of their operation characterized by service conditions [4].
The main reason of the change in the MWR technical condition is the oil temperature exceeding the critical value. Study on the determination of the effect of operating conditions on thermal operating mode MWR trucks revealed a large number of their repairs and downtime associated with them, losses in mining. The bulk of the failures caused by cracks and faults of the various systems of vehicle, most of which is accounted for by the carrier system (28\%) [5]. More than one third of these outages is caused by failures of MWR [6].

The aim of the work is to define the impact of dump trucks loading on the thermal regime of work and the reliability of their gearboxes geared wheels. To achieve this goal it is necessary to solve the following tasks:

-to highlight the factors influencing the thermal mode of operation to assess MWR significance;

-to develop the regression model of oil MWR temperature factors;

-to set idle duration dependence of dump trucks in the repairing of thermal operating mode of the MWR and, as a consequence, the degree of their downloads for their specific application and environmental conditions.

\section{II.OBJECT OF STUDY}

The object of study is the temperature regime of MWR of dump trucks, as well as the nature of its impact on the technical condition and operational efficiency of quarry dump trucks.

The scientific novelty of this work is:

-in determining the effect of oil temperature of MWR performance indicators, the main of which is the utilization of tonnage;

-development of a regression model to determine the impact of major performance indicators at temperature MWR;

-in establishing reliability of reducer dependency and oil temperature of utilization.

In the work, the methods of statistical data processing, regression models designing, analysis and synthesis, mathematical modelling and programming were used.

The main works in the field of improving the reliability and efficiency of vehicles are written by the scientists: M. Vasilyev [7], A. Kuleshov [8], M. Potapov, V. Smirnov [9]. The 
studiesare given by A. Vernatckiy, E. Pochetny, A. Rakitskiy and A. Kazarez [10]. One of the leading specialists in the field of reliability and quality of mining machines G. Solod [11] suggested the technique of out-of expert quality assessment of mining machines.

The author of work [12] notes that the experience of the operation of car transmissions shows that their performance greatly depends on the thermal state of the units, which operate in a wide range of temperatures. Despite the good conditions of their cooling systems, there are cases when the oil temperature exceeds $120^{\circ} \mathrm{C}$ and even $170^{\circ} \mathrm{C}$.

Studies show that decreasing the reliability of mining equipment units with a closed lubrication system is due to deterioration of units, the qualitative change of the working oil properties [13].

Working oil carries comprehensive information that enables you not only to diagnose and predict the technical condition of the object, but also describe the various processes, giving the opportunity to identify the causes of reduced reliability and evaluate them quantitatively [14].

Also it was [13] found out that the technical condition of the gearboxes is objective to assess the working oil temperature, critical which is $120^{\circ} \mathrm{C}$.

It should be noticed that no works dedicated to the development of the model determine the rational utilization of tonnage, taking into account temperature mode MWR trucks. Therefore, the development of this model is a challenge. The need to develop models caused by increasingly complex mining and geological conditions of the digger-car systems work, which affects the thermal state of the MWR trucks.

\section{METHODS}

When evaluating the thermal operating mode of MWR as major influencing factors, the following indicators: the utilization rate $(\gamma \mathrm{gr})$, which characterizes the loading of vehicles; the distance of transportation of cargo (Leg); inclination (i); ambient temperature (tov).

Experimental research on determination of the effect of operating conditions on the thermal regime of the gearboxes motor-wheels trucks was carried out in the context of OJSC «Taldinskij» branch of the colliery company "Kuzbassrazrezugol". For the objectivity and accuracy of the data, 2-yearsstudies were conducted giving an opportunity to evaluate the testimony during different seasons.

For experimental studies measuring instruments have been used. The temperature was estimated in two ways and MWR with two devices with a high enough accuracy and low error: the first method is to record oil temperature of MWR through the filler cap using a digital device-digital multimeter CMM40 .

After stopping the truck and unloading operations, special sensors measured oil temperature. This method was more labor intensive and required additional time to measure the oil temperature.
The second method is recorded directly to the gearbox casing temperature by means of an infrared device-infrared non pyrometer Center 350 .

It was studied that the temperature difference between oil and shell MWR temperature and when measured between the two appliances amounted to $16^{\circ} \mathrm{C}$. To eliminate any additional downtime for dump trucks, temperature measurements were conducted in the second way, then add this value to the results. At the initial stage of the observations there were measurements of oil temperature in both units. It was found that these values are practically identical, further measurements were carried out only with the right gear.

The studies were conducted once and had the goal to optimize maintenance intervals and regulated repair trucks.

\section{RESULTS AND DISCUSSION}

As already mentioned above, low oil MWR (tm) is the most informative indicator of its technical condition. In the event of overheating, the oil loses its properties, and an increased wear of the mating surfaces and parts takes place. Under thermal refers to changing the oil MWR temperature in the various conditions of use of trucks.

Despite the cooling, the maximum, and often the average oil temperature values in MWR exceed critical value of $120^{\circ} \mathrm{C}$. The maximum value of the oil temperature in the MWR recorded in summer time (at an ambient temperature of about 300c) at the level of $161^{\circ} \mathrm{C}(\mathrm{BELAZ-75302)}$ [15]. In such temperatures viscosity and other properties of the oils become worse, deteriorating working conditions for all elements. As well as the reliability of all components and units greatly depends on the thermal regime of work, foresight and maintaining oil temperature permitted limits is an urgent task that will maintain in technically serviceable condition.

To assess the importance of the studied parameters calculated correlation coefficients characterizing the degree of influence on the temperature of the oil in the gearboxes. The values of the coefficients are defined for the most common models of trucks and for generalized coupled "All Belaz».

Analysis of the obtained values (fig. 1) shows that the closest relationship has been observed between oil temperature and ambient air temperature IMC, as well as between oil temperature MWR and utilization of capacity. Thus, the greatest influence on temperature change of oil in the gearboxes motor-wheels trucks have these two, the above indicators [16].

There is a possibility to change only one of the two factors (utilization), because the potential impact on the ambient air temperature is not present, the day-to-day management of this indicator will allow for all operating conditions to develop such recommendations, in which the resource is to be maximised. MWR, however, neglect the rest considered indicators, as they also affect oil temperature MWR. Therefore, the most reliable will review the impact of the totality of the indicators, which necessitates the establishment of regression model. 


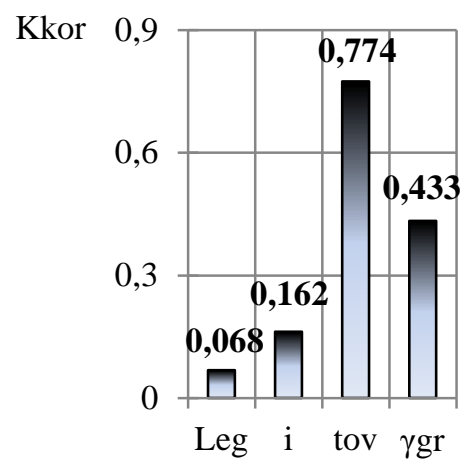

Fig. 1. The value of the correlation coefficient (Kkor) to select "All Belaz»

To improve the accuracy of the calculations of coefficients of correlation were carried out identification method of least squares for all car groups: BELAZ-75131-75302-75306 and All Belaz».

The calculations and data processing were obtained to determine the empirical work on oil temperature when operating vehicles in MWR various conditions shown in the table.

TABLE-regression equations for samples of dump trucks BELAZ in groups

\begin{tabular}{|c|c|}
\hline $\begin{array}{l}\text { Sample } \\
\text { group }\end{array}$ & The obtained regression equation \\
\hline $\begin{array}{l}\text { BELAZ- } \\
75131\end{array}$ & $\begin{array}{c}t_{m}=51,74+35,9 \cdot \gamma_{\text {гр }}+0,77 \cdot t_{\mathrm{oc}}+1,03 \cdot L_{\text {ег }} \\
+1,95 \cdot i\end{array}$ \\
\hline $\begin{array}{l}\text { BELAZ- } \\
75302\end{array}$ & $\begin{array}{c}t_{m}=89,77+27,07 \cdot \gamma_{\text {гр }}+0,92 \cdot t_{\mathrm{oc}}+1,38 \cdot L_{\mathrm{er}} \\
+1,73 \cdot i\end{array}$ \\
\hline $\begin{array}{l}\text { BELAZ- } \\
75306\end{array}$ & $\begin{array}{c}t_{m}=70,72+22,99 \cdot \gamma_{\mathrm{rp}}+0,94 \cdot t_{\mathrm{oc}}+1,12 \cdot L_{\mathrm{er}} \\
+1,28 \cdot i\end{array}$ \\
\hline $\begin{array}{l}\text { «All } \\
\text { BELAZ » }\end{array}$ & $\begin{array}{c}t_{m}=70,83+27,09 \cdot \gamma_{\mathrm{rp}}+1,04 \cdot t_{\mathrm{oc}}+0,38 \cdot L_{\mathrm{er}} \\
+1,43 \cdot i\end{array}$ \\
\hline
\end{tabular}

To determine the error of the regression equations used the Fisher criterion. Analysis of calculations showed: 0.95 probability it can be argued that engagements are statistically significant regression [17].

As demonstrated by the analysis of dependencies, regression equation for "All BELAZ » has little error compared to the other three equations, so for further calculations use the general formula, which describes the thermal operating mode MWR for all car brands particularly heavy-duty [18]:

$t_{m}=70,83+27,09 \cdot \gamma_{g r}+1,04 \cdot t_{o v}+0,38 \cdot L_{e g}+1,43 \cdot i$

The next step in determining the dependencies of the car stopping in a State of disrepair $\left(D_{\text {rep }}\right)$ from the utilization of tonnage is the definition of functions such as: $D_{\text {rep }}=f\left(t_{m}\right)$.

Thanks to the use of oil as a parameter to determine the thermal regime MWR career cars, you can solve such tasks as:

- reduce downtime due to failure of the MWR;

- reduced costs for current repair MWR;

- reduction of days of downtime in repair.

To determine the numerical values of the parameters of the equation used the method of least square spacecraft, searched for a solution and solved the system of normal equations.

To describe the dependency of the exponential function is selected:

$$
y=a_{1} \cdot e^{a_{2} \cdot x}
$$

To determine the coefficients a 1 and a 2 exponential correlation equations system of normal equations is as follows:

$$
\left\{\begin{array}{c}
\sum \ln y=n \cdot \ln a_{1}+a_{2} \cdot \sum x \\
\sum x \ln y=\ln a_{1} \cdot \sum x+a_{2} \cdot \sum x^{2}
\end{array}\right.
$$

wheren is the number of measurements.

As a result, it was determined that the downtime of the vehicle repair $\left(D_{\text {rep }}\right)$ due to the refusal of gearboxes is determined by the formula:

$$
D_{\text {rep }}=0,0093 \cdot e^{0,0555 \cdot t_{m}} \text {. }
$$

Thus, the goals of this work are achieved. Namely, the interrelation between loading and thermal regime were the career of its gearboxes geared wheels. As well as, determined the dependence of duration of idle trucks in disrepair, due to fault in gearboxes, from utilization of capacity.

\section{CONCLUSION}

Using the regression equation and, as an example, calculated for specific operating conditions in the open-pit "Taldinsky", which showed that while lowering the oil temperature from the critical value at $25 \%$, the number of gearbox failures is reduced by more than $20 \%$, while increasing the maximum observed value $\left(161^{\circ}\right)$-increases 9 times.

Thus, using this method for determining rational work load, taking into account the thermal mode of operation of gearboxes geared wheels, it is possible to define the modes of operation of heavy trucks, in which maximum reliability and long service life. However, if you change at least one of the conditions for exploitation of results have to recalculate that considerably cumbersome, given the number of formulas in the methodology. Therefore, it is advisable to develop a simulation model that will allow to identify quickly the rational utilization of carrying capacity value in different conditions.

\section{REFERENCES}

[1] Mariev P.A., Kuleshov A.A., Egorov A.N., Zyrianov I.V. Openpitvehicles: status and prospects. Spb, Nauka, 2004, pp: 429.

[2] Anistratov K.Y. Gradysov M.S., Stremilov V.I., Teterin M.V. Study patterns of performance change of dump trucks during their lifetime. Mining, 2006, No. 6

[3] Berdick B.G. Lubricating oil as a design element, nondestructive testing and Diagnostics technology in operation as of controls. Diagnostics, 2005, No. 5, pp: 23-26.

[4] Bogdanov S.A. Development of a method to determine the change of the technical state of transmission units of automobiles on thermal condition indicators//Katege. atsoisk. Ouch. the degree Cand. Tech. Sciences. Kharkov, 1987, 23 since.

[5] Kabikenov S.J., Intykov T.S., Kyzylbaeva E.J. Methodology for collecting and processing information on the reliability of components and units of dump trucks. Mountain magazine, 2015, No. 9.

[6] Ishin N.N. Goman A.M., Skorokhodov A.S, Truhnov L.I. Evaluation of the level of vibration and residual resource of gearboxes motor-wheel dump trucks BELAZ. Mining magazine, 2014. No. 9. 
[7] Vasilyev M.V., Smirnov V.P., Kuleshov A.A. Exploitation of mining vehicles. Moscow. Nedra. 1979. pp:280.

[8] Kuleshov A.A. Choice of optimal structure tipagnoj Digger-car systems for career-specific conditions. Leningrad. 1989. pp: 70.

[9] Smirnov V.P., Lel. Y.I. Theory of open-pit transport. Ekaterinburg. URO RAN. 2002. pp:355.

[10] Kazarez A.A., Kuleshov A.A. Operation of the quarry dump trucks with electromechanical transmission.. M.: Nedra. 1988. pp: 264.

[11] Solod G.I., Shakhova K.I., Rusihin V. I. The increase of durability of mining machines. Moscow. Mashinostroenie. 1979. pp: 184

[12] Zaitsev A.V. Development of a method for thermal driving axles. Katege. Dees. ... Cand.Tech. Sciences. -BARROW, 1999.-19 p

[13] Kudrevatykh A.V. Substantiation of methods and parameters for the diagnosis of gearboxes Digger-automotive complexes: DIS. ... Cand.Tech. Sciences. Kemerovo. 2010. pp:187.

[14] Ababkov N.V. Research of structure and properties of metal shell gearbox wheel motor hub of BELAZ-7555 after repair. Vestnik Kuzbass. gosud. tehn. univ.. 2016. No. 1. pp: 129-135
[15] Khoreshok A.A. Stenin D.V., Stenina N.A. Influence of operating conditions on the thermal state of the gearboxes motor-wheel dump trucks Belaz. Vestnik Kuzbass. gosud. tehn. univ.2012. No 2. pp: 28-30.

[16] Stenina N.A., Stenin D.V., Khoreshok A.A. Valuing the investigated parameters that affect the loading gearboxes motor-wheels (MWR) quarry dump trucks. Young Russia: proceedings of the IV all-Russian, 57 Scientific Conference of young scientists. KuzSTU. Kemerovo. 2012. pp:319321.

[17] Efimova M.P., Ganchenko O.I., Petrova E.V. A workshop on general theory of statistics. Moscow. Finansy I Statistika. 2001. pp:208.

[18] Stenin D.V., Stenina N.A. Using correlation analysis when evaluating the thermal state of the gearboxes motor-wheel dump trucks Belaz career. Natural and intellectual resources of Siberia: materials IX international scientific-practical Conference "SIBRESURS 2012". Kemerovo. 2012. pp: $133-137$.

[19] Ababkov N.V., Bakanov A.A. The research of structure and properties of the hub shell metal of gear-motor whell of Belaz 7555 after repair. Vestnik Kuzbass. gosud. tehn. univ.2016. No 1. pp: 129-134. 